\title{
Divergent Water Sources of Three Dominant Plant species following Precipitation Events in Enclosed and Mowing Grassland Steppes
}

\author{
Tiejun Bao ${ }^{1,2,3}$, Yunnuan Zheng ${ }^{1,2,3}$, Ze Zhang ${ }^{1,2,3}$, Heyang Sun ${ }^{1,2,3}$, Ran Chao ${ }^{1,2,3}$, Liqing Zhao ${ }^{1,2,3}$, Hua Qing ${ }^{1,2,3}$, \\ Jie Yang ${ }^{\text {Corresp., 1, 2, } 3}$, Frank Yonghong Li ${ }^{1,2,3}$ \\ 1 Inner Mongolia University, School of Ecology and Environment, Hohhot, China \\ 2 Inner Monoglia University, Ministry of Education Key Laboratory of Ecology and Resource Use of the Mongolian Plateau, Hohhot, China \\ 3 Inner Monoglia University, Inner Mongolia Key Laboratory of Grassland Ecology, School of Ecology and Environment, Hohhot, China \\ Corresponding Author: Jie Yang \\ Email address: jyang@imu.edu.cn
}

Understanding of the dynamic patterns of plant water use in a changing environment is one of foci in plant ecology, and can provide basis for the development of best practice in restoration and protection of ecosystem. We studied the water use sources of three coexisting dominant plant species Leymus chinensis, Stipa grandis and Cleistogenes squarrosa growing in both enclosed and mowing grassland in a typical steppe. The oxygen stable isotope ratios $\left(\delta^{18} O\right)$ of soil water and stem water of these three species were determined, along with soil moisture, before and after precipitation events. The results showed that (1) mowing had no significant effect on the soil moisture and its $\delta^{18} 0$, whereas precipitation significantly changed the soil moisture though no significant effect detected on its $\delta^{18} \mathrm{O}$. (2) C. squarrosa took up water majorly from top soil layer due to its shaollow root system; L. chinensis took up relative more water from deep soil layer, and S. grandis took up water from the middle to deep soil layers. (3) L. chinensis and S. grandis in mowing grassland tended to take up more water from the upper soil layers following precipitation events, but showed no sensitive change in water source from soil profile following the precipitation in the enclosed grassland, indicating a more sensitive change of soil water sources for the two species in mowing than enclosed grassland. The differences in root morphology and precipitation distribution may partly explain the differences in their water uptake from different soil layers. Our results have important theoretical values for understanding the water competition among plants in fluctuating environment and under different land use in the typical steppe. 


\section{Divergent Water Sources of Three Dominant Plant species}

\section{2 following Precipitation Events in Enclosed and Mowing}

\section{Grassland Steppes}

Tiejun Bao ${ }^{1,2,3}$, Yunnuan Zheng ${ }^{1,2,3}$, Ze Zhang ${ }^{1,2,3}$, Heyang Sun ${ }^{1,2,3}$, Ran Chao ${ }^{1,2,3}$, Liqing Zhao ${ }^{1,2,3}$, Hua Qing ${ }^{1,2,3}$, Jie Yang ${ }^{1,2,3}$, Frank Yonghong Li ${ }^{1,2,3}$

${ }^{1}$ School of Ecology and Environment, Inner Mongolia University, Hohhot 010021, China;

${ }^{2}$ Ministry of Education Key Laboratory of Ecology and Resource Use of the Mongolian Plateau, Inner Monoglia University, Hohhot, 010021, China;

${ }^{3}$ Inner Mongolia Key Laboratory of Grassland Ecology, School of Ecology and Environment, Inner Monoglia University, Hohhot, 010021, China.

Corresponding Author:Jie Yang1,2,3

Street Address, Hohhot,Inner Mongolia, 010010, China

Email address:jyang@mail.imu.edu.cn

\section{Abstract}

Understanding of the dynamic patterns of plant water use in a changing environment is one of foci in plant ecology, and can provide basis for the development of best practice in restoration and protection of ecosystem. We studied the water use sources of three coexisting dominant plant species Leymus chinensis, Stipa grandis and Cleistogenes squarrosa growing in both enclosed and mowing grassland in a typical steppe. The oxygen stable isotope ratios $\left(\delta^{18} \mathrm{O}\right)$ of soil water and stem water of these three species were determined, along with soil moisture, before and after precipitation events. The results showed that (1) mowing had no significant effect on the soil moisture and its $\delta^{18} \mathrm{O}$, whereas precipitation significantly changed the soil moisture though no significant effect detected on its $\delta^{18} \mathrm{O}$. (2) $C$. squarrosa took up water majorly from top soil layer due to its shaollow root system; L. chinensis took up relative more water from deep soil layer, and S. grandis took up water from the middle to deep soil layers. (3) L. chinensis and S. grandis in mowing grassland tended to take up more water from the upper soil layers following precipitation events, but showed no sensitive change in water source from soil profile following the precipitation in the enclosed grassland, indicating a more sensitive change of soil water sources for the two species in mowing than enclosed grassland. The differences in root morphology and precipitation distribution may partly explain the differences in 
their water uptake from different soil layers. Our results have important theoretical values for understanding the water competition among plants in fluctuating environment and under different land use in the typical steppe.

Keywords: Steppe; Dominant plants; Water sources; Mowing; Oxygen stable isotopes

\section{Introduction}

Utilization of different water sources by plants is one of key mechanisms underlying plant species coexistence and plant community construction (Zhang et al., 2014). The main water sources for plant utilization are precipitation, soil water, runoff water and groundwater (Duan et al., 2007). The proportion of various water sources in plant water uptake depends on many factors, such as topography, land use type, soil texture and the pattern, intensity and frequency of precipitation. For example, it was observed that a single strong precipitation event could increase the availability of the water in deep soil layers, which in turn facilitated the growth of deeprooted plant species (Nippert et al., 2007; Goldstein et al., 2014). Plants have varied utilization efficiencies for various water sources in different ecosystems. In the desert ecosystem of southern Utah, USA, Ehleringer et al. (1991) found that the growth of annual and perennial succulent plants depended entirely on summer precipitation, whereas herbaceous and perennial woody plants could use both summer and winter-spring precipitation, with herbaceous plants having more dependence on summer precipitation. Analyzing plant water sources helps understanding of the adaptation mechanisms used by different species to cope with the arid environment, thus providing a basis for accurately addressing the root water uptake when constructing hydrological models. In addition, these analyses can also, according to the spatial and temporal differences in plant water sources, provide guidance for species selection and matching in revegetation to avoid excessive competition among species. Currently, the studies about the use of water sources by plants have been widely conducted in deserts, temperate forests (Halliday et al., 2011), Mediterranean-type deserts (Matimati et al., 2013) and coasts (Mccole et al., 2007; Corbin et al., 2005).

The temperate semi-arid steppe is one of the most important ecosystems in the world, covers approximately one-fifth of land surface, and the typical steppe covers $10.5 \%$ of the territory in China (Wang et al, 2011). Precipitation is largely the only water source in semi-arid steppe ecosystems, so the water consumed by plants is mainly from soil water after the redistribution of precipitation in soil. For example, the deep-rooted shrub Caragana microphylla mainly utilizes 
59

60

water from deep soil layer that is derived from winter snowfall and heavy precipitation; whereas the shallow-rooted grass Cleistogenes squarrosa mainly utilizes surface soil water that is dependent on summer precipitation (Yang et al., 2011). Mowing (for hay) is one of the main utilization modes of semi-arid steppes. Mowing not only affects the redistribution of precipitation in the soil by affecting the canopy structure of the community(Zhang et al.,2014; Wang et al.,2015), but also affects the functional traits of plant roots(Zhang et al.,2014), and these changes would inevitably affect the water sources of dominant plant species. Compared with other ecosystems, the semi-arid steppe ecosystem is more sensitive to changes of water resources (Lioubimtseva et al., 2005; Zhou et al., 2005), and more responsive to transient fluctuations in resource availability (Zhang et al., 2014). Therefore, understanding the mechanisms of plant water use is essential to steppe management by exploring how dominant plants respond to instantaneous precipitation events and use available water resources in enclosed and mowing conditions.

Traditional methods of studying plant water sources were difficult, such as root excavation could determine the available water sources but the main water sources cannot be determined, because the existence of roots does not mean that these roots are active in water absorption (Flanagan et al. 1992). Comparatively, stable isotope technology has high sensitivity and accuracy, and has wide applications in the study of water sources and water use efficiency of plants in natural ecosystems (Yoder and Nowak 1999; Vandenschrick et al. 2002; Schwinning et al. 2005; Nippert and Knapp 2007; Goldstein and Suding, 2014). In this study, we aimed to explore how the three coexisting dominant species Stipa grandis, Leymus chinensis and $C$. squarrosa in a typical steppe community respond to summer precipitation events in water use under two grassland utilization modes (mowing and enclosed). The typical steppe, dominated by S. grandis, L.chinensis, S. krylovii, and Cleistogenes squarrosa (Bai et al, 2008). We determined the oxygen stable isotope ratios $\left(\delta^{18} \mathrm{O}\right)$ of soil water and stem water of these three plants, and soil water content before and after precipitation events in the mowing and enclosure plots. The results would reveal the water use pattern and the competition relationship of plants in the typical steppe, and have important theoretical significance for understanding the relationship between plants and the environment under degradation in arid and semi-arid regions.

\section{Materials and Methods}

\section{Study area}

This experiment was conducted in the Grassland Ecosystem Research Station of the Inner Mongolia University, located $40 \mathrm{~km}$ east of Xilinhot city in Central Inner Mongolia, China 
$92\left(116^{\circ} 2^{\prime}-116^{\circ} 30^{\prime} \mathrm{E}, 44^{\circ} 48^{\prime}-44^{\circ} 49^{\prime} \mathrm{N}, 1101 \mathrm{~m}\right.$ asl). The region experiences a temperate semi-arid 93 climate, with a mean annual temperature of $2.6^{\circ} \mathrm{C}$, the annual accumulated temperature of 2412 $94{ }^{\circ} \mathrm{C}\left(>0{ }^{\circ} \mathrm{C}\right)$, and the average period of plant growth approximately 150 days; mean annual precipitation is between $200 \mathrm{~mm}$ to $350 \mathrm{~mm}, 78 \%$ of which falls between June to September, and the annual evaporation is 1600-1800 mm (Wan et al., 2016; Bai et al., 2018). The major soil type is a sandy loam chestnut soil, equivalent to Calcic-orthic Aridisol in the US soil taxonomy classification system.

The vegetations in the study region are largely dominated by $S$. grandis, with L. chinense and C. squarrosa as major species. The enclosure and mowing plots were started in 2011 to study the effects of annual mowing on native steppe. Eight $20 \mathrm{~m} \times 30 \mathrm{~m}$ experimental plots (four enclosure and four mowing plots) were established with a distance of $5 \mathrm{~m}$ between any two plots. The mowing treatment was performed on August $20^{\text {th }}$ of each year and begin from 2011.

\section{Sample collection}

Two precipitation events were recorded in July 2016, a light precipitation event of $10.8 \mathrm{~mm}$ on 29 July and a medium precipitation event of $20.0 \mathrm{~mm}$ on 30 July. Samples were collected separately on the day before these precipitation events (28th July) and on the first and fifth day after precipitation (31st July and 4th August) from each experimental plot. Non-photosynthetic tissues of plant from the interface between shoot and root systems were collected for the analysis of oxygen stable isotope ratios (Thorburn et al., 1993). For each plant species, the nonphotosynthetic tissues from at least 20 individuals were collected in each plot and combined as one replicate, enclosed in the screw-capped glass vial, immediately sealed with Parafilm, and then stored at $-20{ }^{\circ} \mathrm{C}$ for further stable oxygen isotope analysis.

The soil samples at the depth of 0-5 cm, 5-10 cm, 10-20 cm, 20-40 cm, 40-60 cm, 60-80 cm and $80-100 \mathrm{~cm}$ in each plot were collected with a $5 \mathrm{~cm}$ diameter soil auger. One part of these soil samples was immediately placed into a screw-capped glass vial, sealed with parafilm and then stored at $-20{ }^{\circ} \mathrm{C}$ for stable oxygen isotope analysis. The other part of the soil sample was placed into an aluminum box and weighed to obtain the fresh weight, and then weighed after ovendrying at $105^{\circ} \mathrm{C}$ to get soil water content.

\section{Water extraction and sample analysis}

The water from the soil and plant samples was extracted with a cryogenic vacuum distillation extraction system (Ehleringer et al., 2000). The water isotope analyzer (LGR 9120032, USA) was used to determine the $\delta^{18} \mathrm{O}$ of the extracted water samples with a determination 
124

125

126

127

128

129

130

131

132

133

134

135

136

137

138

139

140

141

142

143

144

145

146

147

148

149

150

151

152

153

154

precision of $0.1 \%$. Three kinds of laboratory working standard water were measured additionally after every three samples against one of them as reference. The isotope ratio of oxygen in water is expressed by the standard delta $(\delta)$ notation in parts per thousand $(\%)$ as follows:

$$
\delta^{18} \mathrm{O}=\left(\mathrm{R}_{\text {sample }}-\mathrm{R}_{\text {standard }}\right) / \mathrm{R}_{\text {standard }} \times 1000
$$

where $\mathrm{R}_{\text {sample }}$ and $\mathrm{R}_{\text {standard }}$ are the molar ratios of ${ }^{18} \mathrm{O} /{ }^{16} \mathrm{O}$ of the water sample and standard water (V-SMOW) respectively.

\section{Data analysis}

Experimental data were analyzed using SPSS Version 19.0 (SPSS Inc., Chicago, USA). Three-way analysis of variance (ANOVA) was conducted to test the effects of the sampling time (ST), mowing (C) and soil depth (SD) on the soil water content and $\delta^{18} \mathrm{O}$ with all of the factors and their interactions being treated as fixed effects. The two-way ANOVA was also used to examine the effects of the sampling time (ST) and mowing (C) on the $\delta^{18} \mathrm{O}$ of plant water. In addition, the differences in the $\delta^{18} \mathrm{O}$ of plant water between the enclosure and mowing treatments were tested using the independent sample t-test.

Potential water sources for the three plant species were divided into four layers of soil water, which are 1) surface water layer $(0-5 \mathrm{~cm}), 2)$ shallow water layer $(5-10 \mathrm{~cm}), 3)$ middle water layer $(10-40 \mathrm{~cm})$ and 4) deep water layer $(40-100 \mathrm{~cm})$. An IsoSource model (Philips \& Gregg, 2003) was used to compare the isotope values of the water in the plant xylem and the isotope values of various potential water sources, and thereby obtaining the feasible ranges of the different water sources used by the three plant species at each sampling time (Phillips et al.,2003). The source increment was defined as $2 \%$, and the mass balance tolerance was defined as $0.01 \%$.

\section{Results and analysis}

\section{Effects of summer precipitation on soil water content in mowing and enclosure steppe}

Soil water content exhibited a very significant change before and after precipitation (Table 1, Fig. 1). As expected, the lowest soil water content appeared before precipitation and the highest soil water content appeared on the first day after precipitation. The changes in the soil water contents with the soil depths were different between the two experiment states. Under the mowing and enclosure treatment, with the increasing soil depth the soil water content increased, except the fifth day after the precipitation in enclosure grassland (Fig. 1). 
155

156

157

158

159

160

161

162

163

164

165

166

167

168

169

170

171

172

173

174

175

176

177

178

179

180

181

182

183

184

185

186

\section{Effects of summer precipitation on $\delta^{18} \mathrm{O}$ of soil water in mowing and enclosure steppe}

Both mowing and the sampling time had no significant effects on the $\delta^{18} \mathrm{O}$ of soil water, but the interaction between the two factors and the soil depth had a significant effect on soil water $\delta^{18} \mathrm{O}$ (Table 2). Compared with the values under the enclosure treatment, the water $\delta^{18} \mathrm{O}$ for the deep layers under the mowing treatment showed a greater fluctuation with the increased sampling interval (Fig. 2). Under both treatments, with the soil depth increasing the $\delta^{18} \mathrm{O}$ of soil water decreased gradually with a reduction from the surface layer to the middle layer of $-5.85 \%$, $-7.31 \%$ and $-8.44 \%$ respectively for the day before the precipitation and the first and fifth day after the precipitation under the mowing treatment, wihile a reduction of $-4.86 \%$, $-7.19 \%$ and $6.78 \%$ separately under the enclosed treatment for the three sampling time.

\section{Effects of mowing and summer precipitation event on the water $\delta^{18} O$ characteristics in} plants

The mowing and sampling times had no significant effects on the water $\delta^{18} \mathrm{O}$ of any one of three plant species $(P>0.05)$, though the largest $\delta^{18} \mathrm{O}$ value of the three plant species appeared on the first day after precipitation (Fig. 3). Under the mowing treatment, the water $\delta^{18} \mathrm{O}$ value of the three plant species ranged from $-8.891 \%$ to $-4.934 \%$ for L chinensis, $-6.73 \%$ to $-5.201 \%$ for S. grandis and from $-2.202 \%$ to $2.062 \%$ for C. squarrosa, with the minimum values of water $\delta^{18} \mathrm{O}$ all occurring before the rainfall. Under the enclosure treatment, the minimum water $\delta^{18} \mathrm{O}$ value of the three plant species all occurred on the fifth day after precipitation, and their water $\delta^{18} \mathrm{O}$ ranged from $-7.709 \%$ to $-6.523 \%$ for L. chinensis, and $-6.584 \%$ to $-4.889 \%$ for $S$. grandis as well as $-2.964 \%$ to $0.132 \%$ for $C$. squarrosa respectively. The isotope values of plant xylem water were similar to those of soil water, indicating that the water in this soil layer is utilized.

\section{Effects of mowing and summer precipitation event on the water sources of the three} dominant plant species

Mowing and precipitation events changed the water sources of the plants (Table 3, Fig. 4). As the estimated range of the proportion that a plant species took up from various soil layers are relatively wide and overlapping, we could not quantify the percentage of water taken up from a specific soil layer. A general pattern in the results (Table 3) was that C. squarrosa took up water majorly from top soil layer, L. chinensis took up relative more water from deep soil layer, and $S$. grandis took up water from the middle layer or from across various layers (Fig.4). Also, For $L$. chinensis and $S$. grandis in mowing grassland, the contribution rate of water form the upper soil 
187

188

189

190

191

192

193

194

195

196

197

198

199

200

201

202

203

204

205

206

207

208

209

210

211

212

213

214

215

216

217

218

219

layer to the plant was separately $50.8 \%$ and $39.9 \%$ on the first day after precipitation, which was higer than those of other soil layers. However, on the fifth day after precipitation, L. chinensis tended to be stabilized to take up water from the shallow to deep soil layers with the ratio ranged from $25.5 \%$ for middle soil layer and $30.2 \%$ for shallow soil layer, while $S$. grandis still took up more water (40.7\%) from the upper soil layer than other soil layers. In contrast, these two species in enclosed grassland showed no sensitive change before and after the precipitation. $C$. squarrosa used the water majorly from the top soil layer either under mowing or in enclosure, and either before and after precipitation events.

\section{Discussion}

Soil water comes primarily from precipitation, and the precipitation amount and pattern drives soil water dynamics (Wang et al., 2013). Combining the characteristics of soil water isotopes with the analysis of soil water content can provide information on the soils role in migration of rainwater. Our results show that the soil water content in the $0-40 \mathrm{~cm}$ soil layer were no significant differences between mowed and enclosed grasslands, either before or after precipitation, which may be related to vegetation cover. Mowing grassland had low vegetation and litter cover, i.e., a high degree of soil exposure, thus may lead to a high evaporation of water from the top soil layer. By contrast, the enclosed grassland has high vegetation and litter cover, and thus the evaporation through soil surface was reduced (Ma et al., 2009). Our results also show that with the increasing soil depth, the soil water content under the mowing treatment gradually increased relative to that of the enclosure treatment. This might be related with dual effects of mowing on water processes in soil profile: the first was a facilitation to water infiltration during the precipitation event because of no litter coverage (Wang et al., 2011); and second was a reduction in water uptake from deep soil layer due to less plant transpiration.

Evaporation would result in the enrichment of $\delta^{18} \mathrm{O}$ in the surface soil water. Our results show that with increasing soil depth, the evaporation decreased, and the isotopic abundance decreased approximately exponentially with the depth until it reached a relatively constant abundance, consistent with the results of Xu et al. (2012). There was no significant difference in the precipitation infiltration or the fractionation degree of evaporation processes between the mowing and enclosure treatments, but the $\delta^{18} \mathrm{O}$ in the soil water at different soil depths under the two treatments were both significantly affected by precipitation. After precipitation, the soil was still affected by intense evaporation. In our study, in shallower soil, the heavy isotope in the soil was enriched and the $\delta^{18} \mathrm{O}$ increased, which agreed with previous studies (Tian et al., 2002; Jin et al., 2015; Wang et al., 2009). Previous studies have shown that L. chinensis and S. grandis 
220

221

222

223

224

225

226

227

228

229

230

231

232

233

234

235

236

237

238

239

240

241

242

243

244

245

246

247

248

249

250

251

252

respond differently to changes in the precipitation amount and pattern. Studies also show that mowing reduces the density, height and biomass of L. chinensis (Guo et al., 2017). In this study, the three dominant plant species L. chinensis, S. grandis and C. squarrosa exhibited a large difference in water source before and after precipitation. Specifically, L. chinensis in mowing grassland used the water majorly from the deep soil layer $(40-100 \mathrm{~cm})$ in dry soil before precipitation, but substantial proportion of water uptake was from top soil layer on the first day after precipitation, and the proportion declined gradually following the precipitation; while $L$. chinensis in enclosed grassland took up water from various soil layers, did not exhibit a large fluctuation. Similarly, $S$. grandis took up proportionally more water from the top soil layer after than before precipitation in mowing grassland, while it showed no much difference in water source before and after precipitation in enclosed grassland. Mowing had no significant effect on the water source of $C$. squarrosa, which utilized soil water majorly from the top soil layer in all cases. Our findings that L. chinensis tends to use more water from deep soil layer in comparison to C. squarrosa and S. grandis, is supported by the findings of Yang et al. (2011). These results also indicate that $L$. chinensis and $S$. grandis in mowing grassland are subject to more severe water deficit in top soil layers before the precipitation (Fig. 1), thus more sensitive to precipitation events than that from natural grassland. However, the rainfall intensity may impact the distribution pattern of the soil water greatly and thus the plant water sources. In our study we only studied the water source of the three species before and after the light and medium rain event, the signatures of which may not adequately describe soil zones explored for water uptake.

The utilization of soil water by plants is closely related to the distribution of plant roots (Xu and $\mathrm{Li}, 2006)$. L. chinensis is a rhizome grass, and its rhizomes are mainly distributed in the 5-10 $\mathrm{cm}$ soil layer, while the roots are mainly in the $0-30 \mathrm{~cm}$ soil layer; $S$. grandis is a tall bunchgrass, and its roots are also concentrated in the $0-30 \mathrm{~cm}$ soil layer. C. squarrosa is a short bunchgrass, with root system concentrated in the $0-10 \mathrm{~cm}$ soil layer(Chen et al.,2001; Ma et al.,1989; Zhu et al., 2004). These differences in root morphology and distribution pattern among these three species may partly explain the observed differences in their water uptake from different soil layers. The difference between the L. chinensis and S. grandis root systems warrants further studies to confirm the observed fact that L. chinensis took up proportionally more water than $S$. grandis from deep soil layers.

\section{Conclusion}

In this study, we explored the water use sources of three coexisting dominant plant species before and after precipitation events including L. chinensis, S. grandis and C. squarrosa growing 
253 in both enclosed and mowing grassland in a typical steppe. We found that the soil moisture and

254 its $\delta^{18} \mathrm{O}$ were not affected by mowing, and only the soil moisture changed significantly after the

255 precipitation. The three dominant plants showed divergent water sources with C. squarrosa

256 generally taking up water from top soil layer, L. chinensis taking up relative more water from

257 deep soil layer, and $S$. grandis just taking up water from the middle to deep soil layers. In

258 addition, L. chinensis and S. grandis in mowing grassland tended to take up more water from the

259 upper soil layers following precipitation events relative to those in the enclosed grassland,

260 indicating a more sensitive change of soil water sources for the two species in mowing than

261 enclosed grassland use. Our results have important theoretical values for understanding the water

262 competition among plants in fluctuating environment and under different land use in the typical

263 steppe.

264

265

266

267

268

269

270

271

272

273

274

275

276

277

278

279

280

281

\section{Acknowledgements}

This study was supported by the National Key Research and Development Program of China (2016YFC0500503), Technical System Project of the National Herbage Industry, China (CARS-34), Major Program of the Natural Scientific Foundation of Inner Mongolia, China (2014ZD02), and Science and Technology Project of Inner Mongolia, China (201502098).

\section{References}

Bai ML, Meng YJ, Dong ZL, Li XC. 2018. Variation Characteristics of $\mathrm{CO}_{2}$ Flux and Its Influence Factors in Typical Grassland Area of Inner Mongolia. Journal of Arid Meteorology, 36 (2): 212-218. (in Chinese)

Bai YF, Wu JG, Xing Q, Pan QM, Huang JH, Yang DL, Han XG. 2008. Primary production and rain use efficiency across a precipitation gradient on the mongolia plateau. Ecology, 89(8), 2140-2153.

Chen SW. 2001. Plant roots of grassland in northern China. Jilin University press. (in Chinese)

Corbin JD, Thomsen MA, Dawson TE, D’Antonio CM. 2005. Summer water use by California coastal prairie grasses: fog, drought, and community composition. Oecologia, 145(4):511-521.

Dawson TE. 1998. Fog in the California redwood forest: ecosystem inputs and use by plants. Oecologia, 117(4): 476-485.

Duan DY, Ouyang H, Song MH, Hu QM. 2007. Water Sources of Dominant Species in Three Alpine Ecosystems on the Tibetan Plateau, China. Abstracts of Ecosummit 2007_ecological Complexity and 
Sustainability_ challenges \& Opportunities for, Century's Ecology, 257-264.

Ehleringer JR, Osmond CB. 2000.Stable isotopes. 2 Plant Physiological Ecology. Springer Netherlands, 12(5):281-300.

Ehleringer JR, Phillips SL, Schuster WSF, Sandquist DR. 1991. Differential utilization of summer rains by desert plants. Oecologia, 88(3): 430-434.

Flanagan LB,Marshall JD, Ehleringer JR. 1993. Photosynthetic gas exchange and the stable isotope composition of leaf water: comparison of a xylem - tapping mistletoe and its host. Plant Cell \& Environment,16(6):623-631.

Goldstein LJ,Suding KN. 2014. Intra-annual rainfall regime shifts competitive interactions between coastal sage scrub and invasive grasses. Ecology, 95(2): 425.

Guo Y. 2017. The influences of different mowing systems on the community community characteristics of Leymus chinensis and water utilization of the xeltala grassland. Inner Mongolia University. (in Chinese)

Halliday M. 2011. Exploring small letter delta 180 in the waters within a temperate forest ecosystem and the evaluation of the peclet effect in a steady state leaf water model.

Jin YR, Lu KX, Li P, Wang Q, Zhang TG, Liu Y. 2015. Research on soil water movement based on stable isotopes. Acta pedologica Sinica, (4):792-801. (in Chinese)

Lioubimtseva E, Cole R, Adams JM, Kapustin G. 2005. Impacts of climate and land-cover changes in arid lands of Central Asia. Journal of Arid Environments, 62(2): 285-308.

Ma CP, Wang HY, Li JB. 2009. Effects of Fencing on Soil Physical and Chemical Properties of Spring Autumn Grassland in Zhaosu Horse Ranch. Agricultural Science Bulletin, 15 (14): 77-80. (in Chinese)

Ma YQ. 1989. Flora of Inner Mongolia. Inner Mongolia University Press. (in Chinese)

Matimati I, Musil CF, Raitt L. 2013. Non rainfall moisture interception by dwarf succulents and their relative abundance in an inland arid South African ecosystem. Ecohydrology, 6(5): 818-825.

Mccole AA, Stern LA. 2007. Seasonal water use patterns of Juniperus ashei, on the Edwards Plateau, Texas, based on stable isotopes in water. Journal of Hydrology, 342(3): 238-248.

Nippert J, Knapp A. 2007. Soil water partitioning contributes to species coexistence in tallgrass prairie. Oikos, 116(6): 1017-1029.

Phillips DL, Gregg JW. 2003. Source partitioning using stable isotopes: coping with too many sources. 
310

311

312

313

314

Oecologia, 136(2): 261-269.

Schwinning S, Starr BI, Ehleringer JR. 2005. Summer and winter drought in a cold desert ecosystem (Colorado Plateau) part II: effects on plant carbon assimilation and growth. Journal of Arid Environments, 61(1):61-78.

Thorburn PJ, Walker GR. 1993.The Source of Water Transpired by Eucalyptus camaldulensis: Soil, Groundwater, or Streams? Stable Isotopes and Plant Carbon-water Relations. 1993: 511-527.

Tian LD, Yao TD, Sun WZ. 2002. Stable isotopic in soil water in the middle of Tibetan Plateau. Acta pedologica Sinica, 39 (3): 289-295. (in Chinese)

Wan ZQ, Yang JY, Gu R, Yan YL, Liang Y, Yang J, Gao QZ. 2016. Effects of different mowing frequency on the community characteristics and soil element contents in a Stipa grandis steppe ecosystem. Acta Ecologica Sinica, 36 (17):5477-5484. (in Chinese)

Wang HY, Liu TX, Wang L, Wu Y, Wang TS, Tong X. 2013. Spatial Variation of Soil Moisture Content in the Dune-meadow Ecotone in the Horqin Sandy Land. Arid zone research, 30 (3):438-443. (in Chinese)

Wang J. 2011. The effect of litter on vegetation and soil moisture in Typical Grassland. (in Chinese)

Wang LH, Liu W, Wang JN, Gan YM, Wu Y. 2015. The compensatory growth of plant community, synusia and species under different clipping intensity. Acta Prataculturae Sinica, 24 (06): 35-42. (in Chinese)

Wang L. 2011. Exchange characteristics of energy and material flux between terrestrial and air in semi-arid grassland ecosystem of Inner Mongolia. Graduate University of Chinese Academy of Sciences. (in Chinese)

Wang SQ, Song XF, Xiao Guo Q, Wang ZM, Liu X, Wang P. 2009. Appliance of oxygen and hydrogen isotope in the process of precipitation infiltration in the shallow groundwater areas of North China Plain. Advances in water science, 20 (4):495-501. (in Chinese)

Vandenschric G, Van WB, Frote. 2002. Using stable isotope analysis $\left(\delta \mathrm{D}-\delta^{18} \mathrm{O}\right)$ to characterise the regional hydrology of the Sierra de Gador, south east Spain. Journal of hydrology, 265:43-55.

$\mathrm{Xu} \mathrm{H,} \mathrm{Li} \mathrm{Y.} \mathrm{2006.} \mathrm{Water-use} \mathrm{strategy} \mathrm{of} \mathrm{three} \mathrm{central} \mathrm{asian} \mathrm{desert} \mathrm{shrubs} \mathrm{and} \mathrm{their} \mathrm{responses} \mathrm{to} \mathrm{rain} \mathrm{pulse}$ events. Plant \& Soil, 285(1/2), 5-17.

Xu Q, Liu SR, Wan XC, Jiang CQ, Song Xf, Wang JX. 2012. Effects of rainfall on soil moisture and water movement in a subalpine dark coniferous forest in southwestern China. Hydrological Processes, 2012, 26(25):3800-3809. 
339 Yang H, Auerswald K, Bai Y, Han XG. 2011. Complementarity in water sources among dominant species in 340 typical steppe ecosystems of Inner Mongolia, China. Plant \& Soil, 340(1-2): 303-313.

341 Yoder CK, Nowak RS. 1999. Soil moisture extraction by evergreen and drought-deciduous shrubs in the 342 Mojave Desert during wet and dry years. Journal of Arid Environments,42(2):0-96.

343 Liu HM, Zhang B, Zhu JJ, Pan QM. 2014. Effects of extreme rainfall and drought events on grassland 344 ecosystems. Chinese Journal of Plant Ecology, 38 (09):1008-1018. (in Chinese)

345 Zhou MT, Li J, Zhu KW. 2015. Changes of NDVI in Different Regions of Northwest Aera and Its Responses to Climate Factor. Research of Soil and water Conservation, 22 (03):182-187. (in Chinese)

347 Zhu TC. 2004. Leymus chinensis bioecology. Jilin science and Technology Press. (in Chinese) 
Figure 1

Characteristics of soil water content before and after precipitation under mowing and enclosure treatments

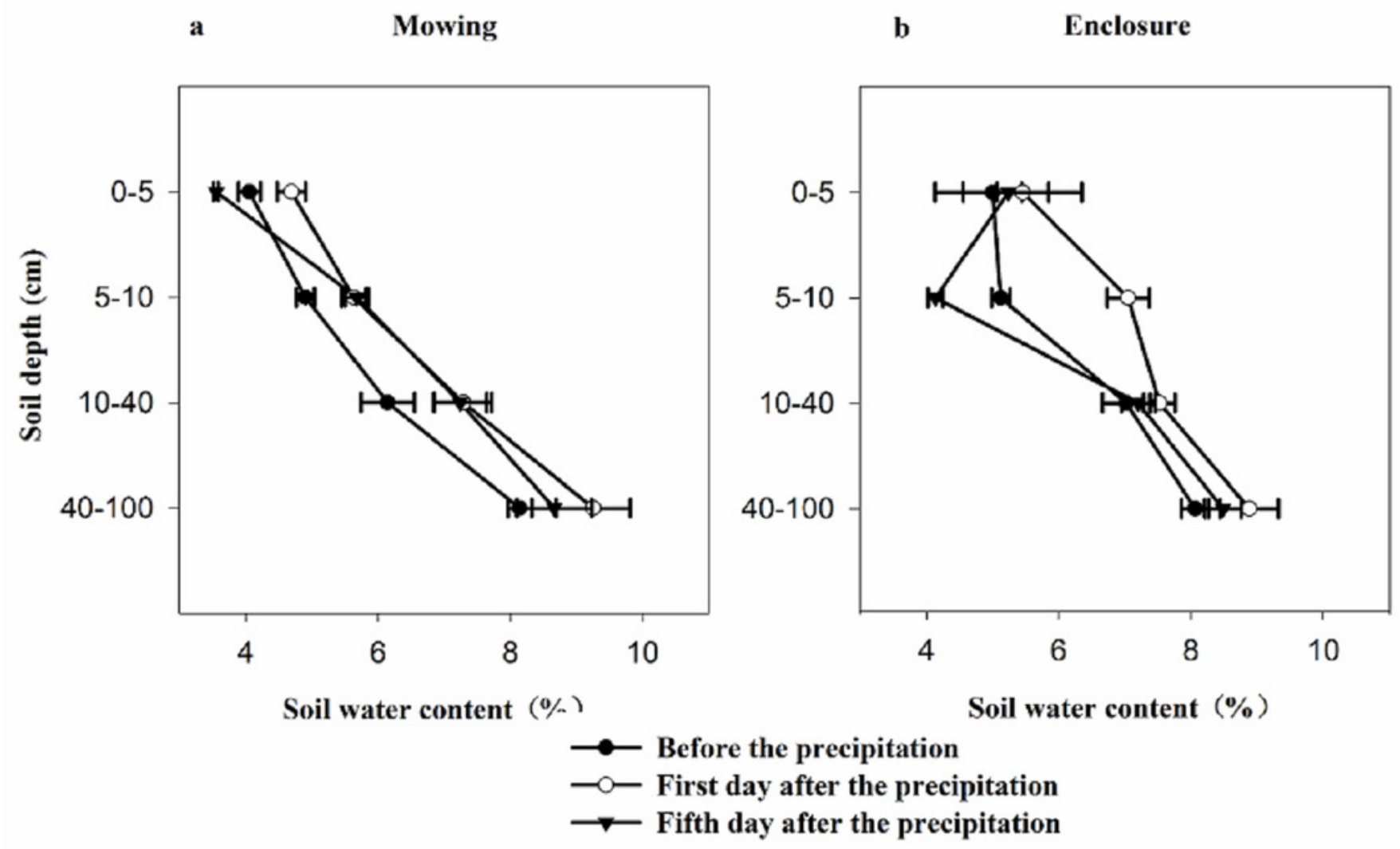


Figure 2

$\delta^{18} \mathrm{O}$ characteristics of soil water before and after precipitation under mowing and enclosure treatments

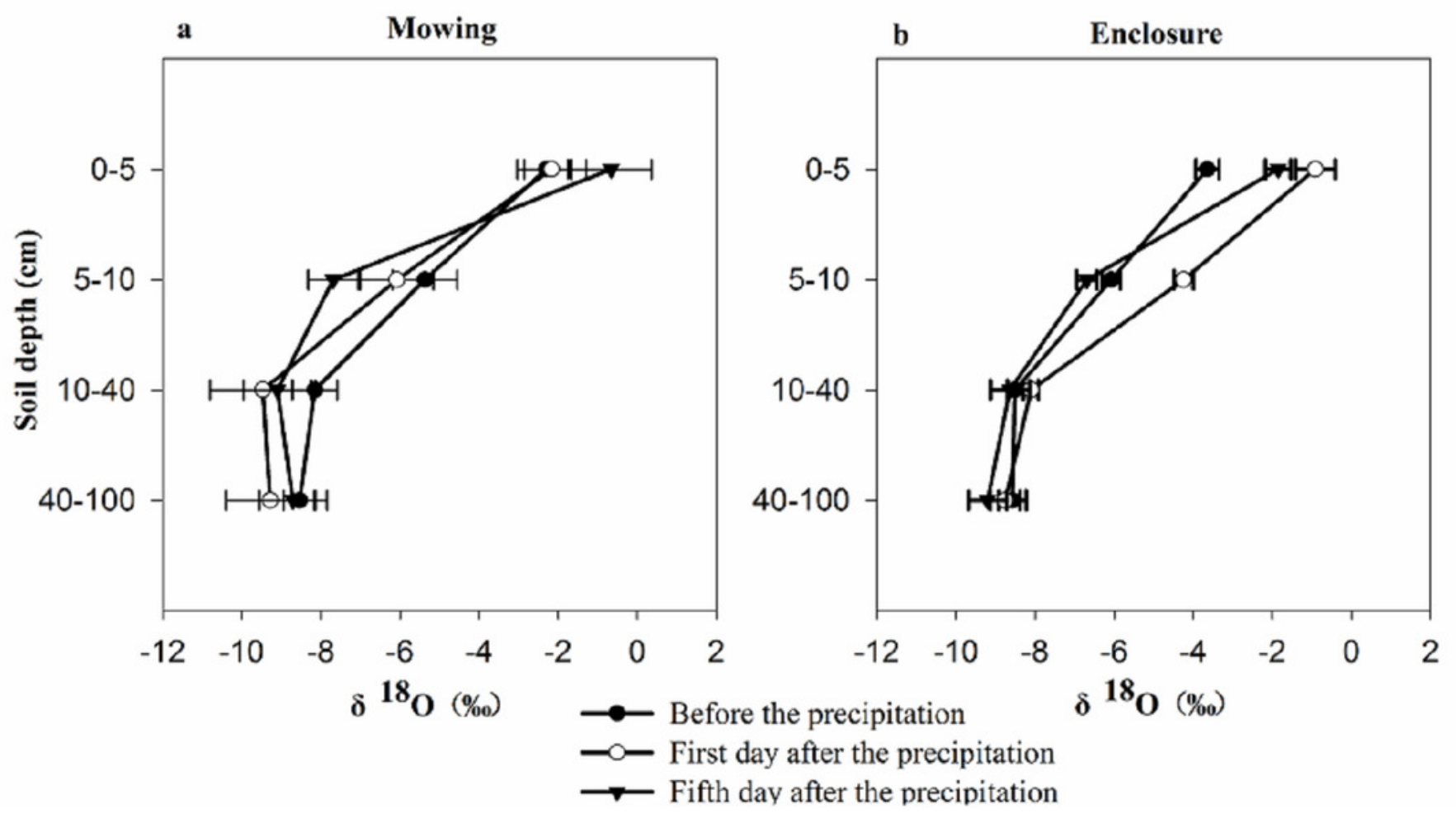


Figure 3

Characteristics of the water $\delta^{18} \mathrm{O}$ in 3 plants before and after precipitation under mowing and enclosure treatments. bpt , before the precipitation; 1datp, the first day after precipitation; 5 datp, the fifth day after precipitation. 

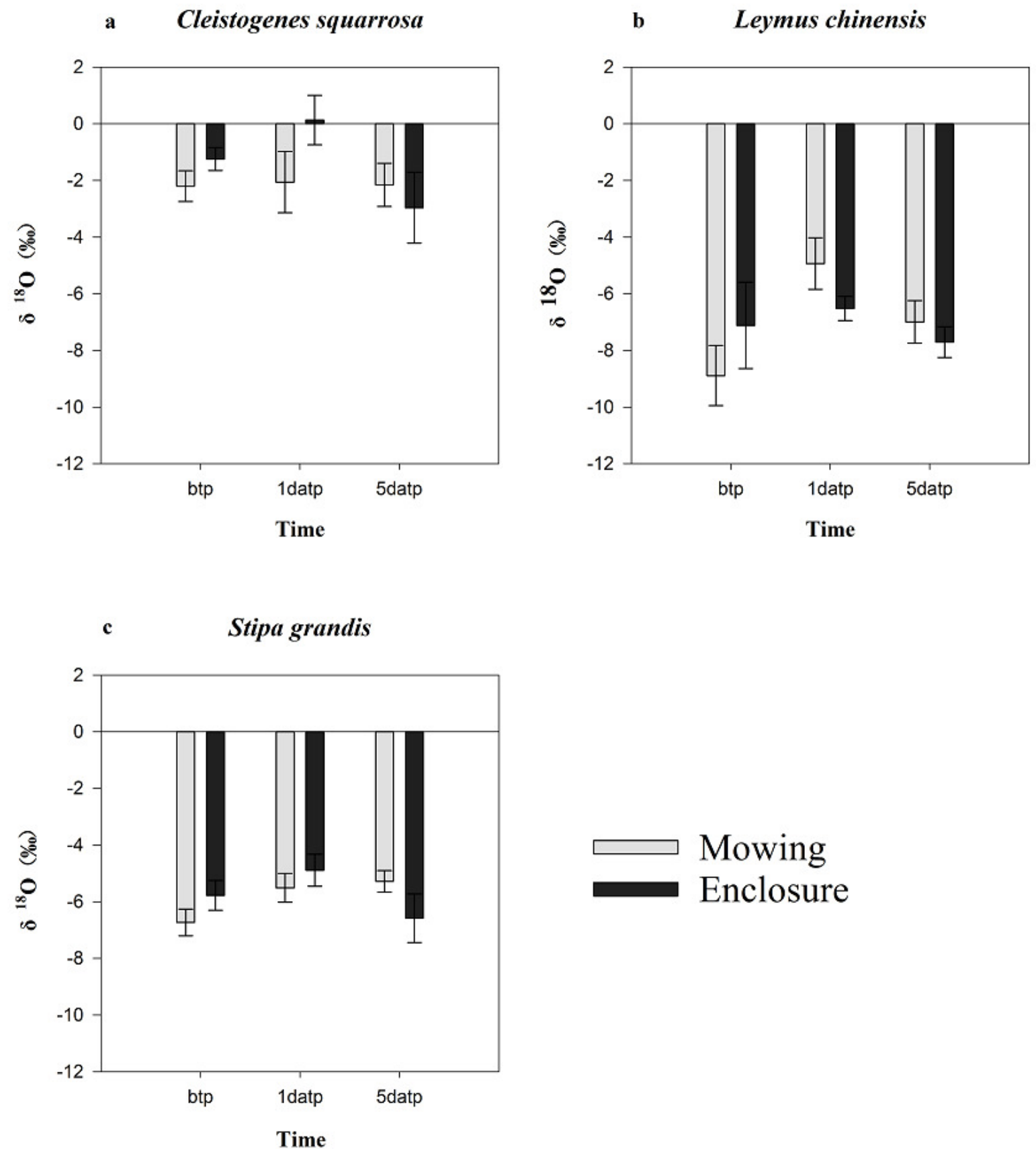
Figure 4

Soil water source of 3 plants under mowing and enclosure treatments before and after precipitation. bpt ,before the precipitation; 1datp, the first day after precipitation; 5 datp, the fifth day after precipitation
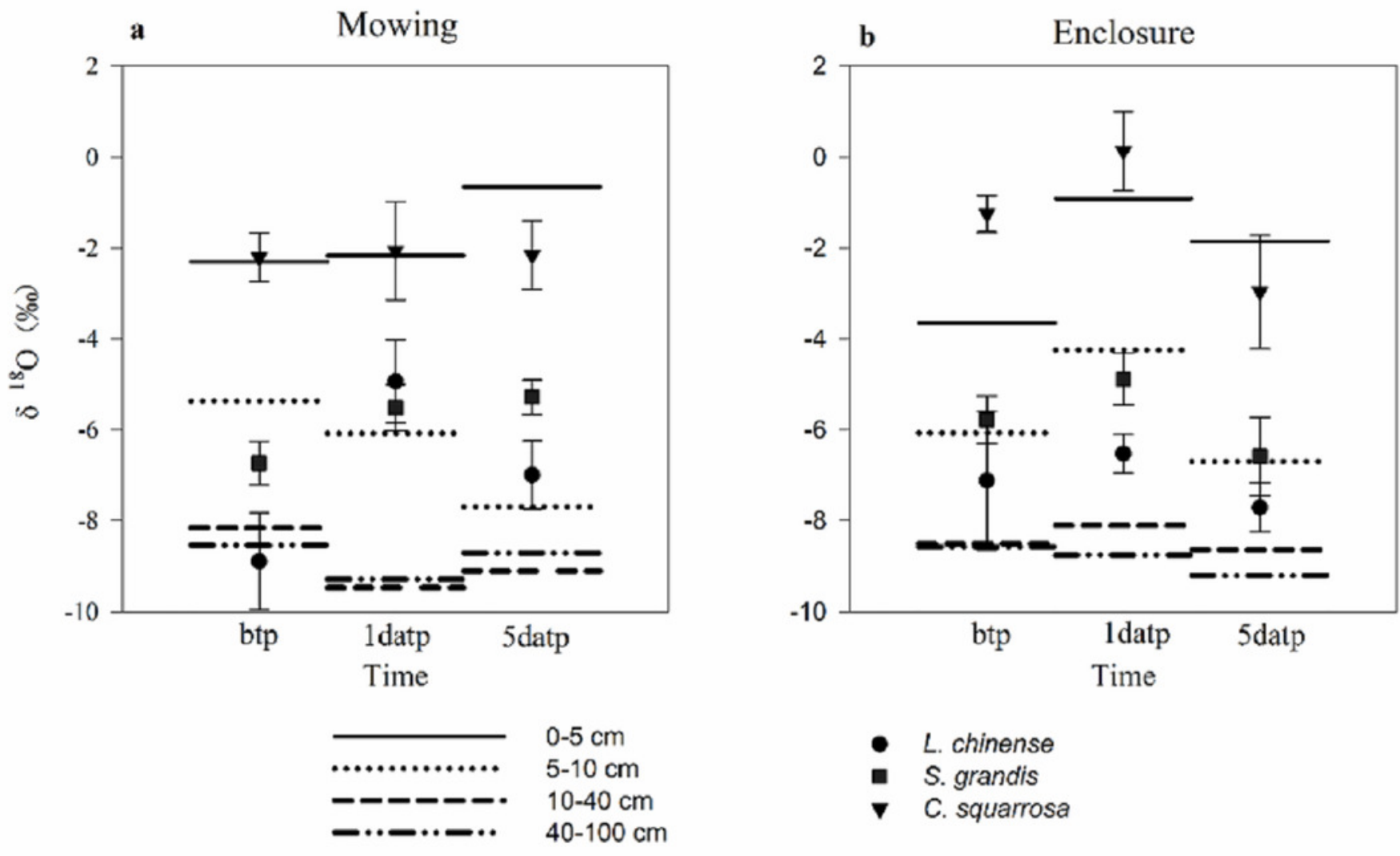


\section{Table 1 (on next page)}

ANOVA result for mowing (C), sampling time (ST) and soil depth (SD) on the soil water content 
Table 1 ANOVA result for mowing (C), sampling time (ST) and soil depth (SD) on the soil water content

\begin{tabular}{|c|c|c|c|c|c|}
\hline Source & $\begin{array}{c}\text { Type III Sum of } \\
\text { Squares }\end{array}$ & df & Mean Square & $\mathrm{F}$ & $P$ \\
\hline $\mathrm{C}$ & 0.000 & 1 & 0.000 & 0.99 & 0.323 \\
\hline ST & 0.002 & 2 & 0.001 & 8.756 & 0.000 \\
\hline SD & 0.028 & 6 & 0.005 & 46.242 & 0.000 \\
\hline $\mathrm{C} * \mathrm{ST}$ & 0.000 & 2 & $5.46 \mathrm{E}-05$ & 0.534 & 0.588 \\
\hline $\mathrm{C} * \mathrm{SD}$ & 0.001 & 6 & 0.000 & 1.320 & 0.257 \\
\hline $\mathrm{ST} * \mathrm{SD}$ & 0.001 & 12 & $8.68 \mathrm{E}-05$ & 0.849 & 0.601 \\
\hline $\mathrm{C} * \mathrm{ST} * \mathrm{SD}$ & 0.001 & 12 & $8.23 \mathrm{E}-05$ & 0.805 & 0.645 \\
\hline Error & 0.009 & 84 & 0.000 & & \\
\hline Total & 0.684 & 126 & & & \\
\hline Corrected total & 0.042 & 125 & & & \\
\hline
\end{tabular}

2 


\section{Table 2 (on next page)}

ANOVA result for mowing (C), sampling time (ST) and soil depth (SD) on soil water $\delta^{18} \mathrm{O}$ 
Table 2 ANOVA result for mowing (C), sampling time (ST) and soil depth (SD) on soil water $\delta^{18} \mathrm{O}$

\begin{tabular}{|c|c|c|c|c|c|}
\hline Source & $\begin{array}{l}\text { Type III Sum of } \\
\text { Squares }\end{array}$ & $\mathrm{df}$ & Mean Square & $\mathrm{F}$ & $p$ \\
\hline $\mathrm{C}$ & 1.237 & 1 & 1.237 & 0.647 & 0.423 \\
\hline ST & 2.371 & 2 & 1.185 & 0.620 & 0.540 \\
\hline SD & 907.113 & 6 & 151.185 & 79.100 & 0.000 \\
\hline $\mathrm{C} * \mathrm{ST}$ & 15.850 & 2 & 7.925 & 4.146 & 0.018 \\
\hline $\mathrm{C} * \mathrm{SD}$ & 7.928 & 6 & 1.321 & 0.691 & 0.657 \\
\hline $\mathrm{ST} * \mathrm{SD}$ & 36.972 & 12 & 3.081 & 1.612 & 0.098 \\
\hline $\mathrm{C} * \mathrm{ST} * \mathrm{SD}$ & 16.185 & 12 & 1.349 & 0.706 & 0.743 \\
\hline Error & 214.067 & 112 & 1.911 & & \\
\hline Total & 9667.259 & 154 & & & \\
\hline Corrected total & 1227.797 & 153 & & & \\
\hline
\end{tabular}

2 


\section{Table 3(on next page)}

Soil water utilization ratio of 3 plants in different soil layer under mowing and enclosure treatments before and after precipitation 
1 Table 3 Soil water utilization ratio of 3 plants in different soil layer under mowing and enclosure treatments before and after 2 precipitation

\begin{tabular}{|c|c|c|c|c|c|c|}
\hline \multirow{2}{*}{ Sample date } & \multirow{2}{*}{$\begin{array}{l}\text { Sample plot } \\
\text { type }\end{array}$} & \multirow{2}{*}{ Plant species } & \multicolumn{4}{|c|}{ The average contribution rate of each potential water source to plants (\%) } \\
\hline & & & $0-5 \mathrm{~cm}$ & $5-10 \mathrm{~cm}$ & $10-40 \mathrm{~cm}$ & $40-100 \mathrm{~cm}$ \\
\hline \multirow{6}{*}{$\begin{array}{c}\text { Before } \\
\text { precipitation }\end{array}$} & \multirow{3}{*}{ Mowing } & L. chinensis & $\bar{\sim}$ & $\bar{\sim}$ & $\bar{\sim}$ & 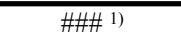 \\
\hline & & S. grandis & $14(0-20)$ & $25.5(0-56)$ & $32(0-66)$ & $28.5(0-70)$ \\
\hline & & C. squarrosa & \#\#\# & $\sim$ & $\sim$ & $\sim$ \\
\hline & \multirow{4}{*}{ Enclosure } & L. chinensis & $14.2(0-28)$ & $29.6(2-58)$ & $22(0-48)$ & $34.2(20-48)$ \\
\hline & & S. grandis & $36.5(12-56)$ & $39(0-88)$ & $20.9(0-44)$ & $3.6(0-8)$ \\
\hline & & C. squarrosa & \#\#\# & $\sim$ & $\sim$ & $\sim$ \\
\hline \multirow{6}{*}{$\begin{array}{l}\text { The first day } \\
\text { after } \\
\text { precipitation }\end{array}$} & & L. chinensis & $50.8(34-62)$ & $23.6(0-60)$ & $14.4(0-38)$ & $11.1(0-30)$ \\
\hline & \multirow[t]{2}{*}{ Mowing } & S. grandis & $39.9(16-54)$ & $29.9(0-82)$ & $15.5(0-44)$ & $14.6(0-46)$ \\
\hline & & C. squarrosa & \#\#\# & $\sim$ & $\sim$ & $\sim$ \\
\hline & \multirow{3}{*}{ Enclosure } & L. chinensis & $13.2(0-28)$ & $21.7(0-48)$ & $33.7(0-78)$ & $31.4(0-68)$ \\
\hline & & S. grandis & $27.1(0-48)$ & $35.9(0-84)$ & $19.2(0-50)$ & $17.8(0-48)$ \\
\hline & & C. squarrosa & \#\#\# & $\sim$ & $\sim$ & $\sim$ \\
\hline \multirow{6}{*}{$\begin{array}{l}\text { The fifth day } \\
\text { after } \\
\text { precipitation }\end{array}$} & \multirow{4}{*}{ Mowing } & L. chinensis & $18.7(10-24)$ & $30.2(0-90)$ & $25.5(0-70)$ & $25.6(0-70)$ \\
\hline & & S. grandis & $40.7(36-44)$ & $21.4(0-54)$ & $18.4(0-48)$ & $19.4(0-54)$ \\
\hline & & C. squarrosa & $80.9(80-82)$ & $7.1(0-14)$ & $7.7(0-16)$ & $4.3(0-10)$ \\
\hline & & L. chinensis & $9(0-20)$ & $25.8(0-58)$ & $33.2(0-82)$ & $32(0-76)$ \\
\hline & \multirow[t]{2}{*}{ Enclosure } & S. grandis & $22.6(4-34)$ & $32.8(0-92)$ & $23(0-64)$ & $21.5(0-60)$ \\
\hline & & C. squarrosa & $81.6(78-84)$ & $8.4(0-20)$ & $5.1(0-12)$ & $4.9(0-12)$ \\
\hline
\end{tabular}

3 Note: The symbol "\#\#" refers to the soil layer where major water source is from for the examined species, as the $\delta^{18} \mathrm{O}$ value of plant stem 4 water is higher than the soil water in top soil layer or lower than bottom soil layer. The symbol " " refers to the soil layer where no water 5 source is from for the examined species. 